\title{
A CONSTRUÇÃO CURRICULAR DE UMA EDUCADORA DE CIÊNCIAS NA EJA: COMO A PRESENÇA DOS JOVENS AFETA A SUA PRÁTICA?
}

\author{
Ana Carolina Costa Resende ${ }^{1}$ \\ - Mariana Cassab² \\ https://orcid.org/0000-0002-5928-1164 \\ https://orcid.org/0000-0001-6991-1804
}

\section{RESUMO:}

A juvenilização é um processo que atinge há décadas a Educação de Jovens e Adultos (EJA), impondo desafios de diferentes ordens. $\mathrm{O}$ trabalho propóe entender como uma professora de Ciências desenvolve sua prática curricular em face da presença dos jovens. Ele se apoia em autores do campo do currículo, como Sacristán e Arroyo e constrói seu contexto de inteligibilidade, se movendo metodologicamente a partir da realização da história oral de vida e de observaçóes de inspiração etnográfica às aulas da EJA. O trabalho conclui que os educandos centralizam a preocupação da professora no sentido de garantir seu interesse, aprendizagem e até mesmo presença na escola. Todavia, isso não significa que as juventudes se manifestam no fazer curricular como princípio estruturador. Há uma tensão em jogo que o estudo procura caracterizar.

\section{THE BUILDING OF THE CURRICULUM OF A SCIENCE TEACHERIN YAE:} HOW DOES THE PRESENCE OF YOUNG PEOPLE AFFECT HER PRACTICE? \section{ABSTRACT:}

Juvenilization is a process that has affected Youth and Adult Education (YAE) for decades, imposing challenges of different orders. This work intends to understand how a science teacher builds her curriculum facing the presence of young people. It relies on authors from the field of curriculum studies, such as Sacristán and Arroyo, building its context of intelligibility by moving methodologically from the narration of the life oral history and ethnographic-inspired observations in the YAE classes. It concludes that the students are central in the teacher's concern, in the sense of guaranteeing their interest, learning and even presence in the school. However, this does not mean that youths appear in the building of the curriculum as a structuring principle. There is a tension at play that the study seeks to characterize.

\section{LA CONSTRUCCIÓN CURRICULAR DE UNA EDUCADORA DE CIENCIAS EN LA EJA: ¿CÓMO LA PRESENCIA DE LOS JÓVENES AFECTA SU PRÁCTICA? RESUMEN:}

La juvenilización es un proceso que ha afectado por décadas la Educación de Jóvenes y Adultos (EJA), imponiéndole diversos desafíos. La investigación pretende comprender cómo una profesora de Ciencias desarrolla su práctica curricular ante la presencia de los jóvenes. Este trabajo tiene como base autores del campo del currículo, como Sacristán y Arroyo, y construye su contexto de inteligibilidad moviéndose metodológicamente a partir de la realización

\author{
Palavra-chave: \\ Juvenilização da EJA; \\ Currículo; Educação \\ de Jovens e Adultos; \\ Educação em Ciências.
}

\section{Keywords:}

Juvenilization of YAE;

Curriculum; Youth and

Adult Education,

Science Education.

Palabras clave:

Juvenilización de la EJA; Currículo; Educación de Jóvenes y Adultos; Educación en Ciencias.

1 Secretaria de Estado de Educação de Minas Gerais, Juiz de Fora, MG, Brasil.

2 Universidade Federal de Juiz de Fora, Juiz de Fora, MG, Brasil. 
de la historia oral de vida y de observaciones de inspiración etnográfica a las clases de EJA. La investigación concluye que los educandos son el centro de la preocupación de la profesora en el sentido de garantizar su interés, aprendizaje e incluso la presencia en la escuela. Sin embargo, esto no significa que las juventudes se manifiesten en el hacer curricular como principio estructurador. Hay una tensión en juego que la investigación busca caracterizar.

\section{INTRODUÇÃO}

Em tempos de vigilância, controle e ataque à escola pública e a seus profissionais, assumir e reafirmar o compromisso com essa instituição e seus sujeitos sociais são tarefas políticas irrefutáveis. A extinção da Secretaria de Educação Continuada, Alfabetização, Diversidade e Inclusão (SECADI) em 2019, o contingenciamento dos recursos destinados à Educação de Jovens e Adultos (EJA) e a intenção de ofertar a modalidade apenas por meio da educação à distância são indícios de uma política em curso que delega à classe trabalhadora uma formação rebaixada ou simplesmente a não escolarização.

Todavia, mesmo diante do cenário de retrocessos que atinge todos os direitos dos pobres e trabalhadores no Brasil, em especial seu direito à educação, precisamos acreditar que é possível mudar o mundo e atuar nessa direção. Afinal, como assevera Paulo Freire (1996), o mundo não é, o mundo está sendo. Nessa luta, um movimento central é observar e compreender com atenção a realidade concreta. Implicar-se no entendimento de como os educadores da EJA, diante das especificidades da modalidade e das condiçóes políticas, administrativas e pedagógicas reais, produzem seus currículos. Assim, esse texto procura trazer para o centro do debate a ação curricular de uma educadora de Ciências, em face do processo de juvenilização que atinge a EJA. Um processo que reconfigura o trabalho docente na modalidade e que, portanto, exige análise pormenorizada.

A literatura do campo expressa com fidedignidade o que os educadores confirmam em suas açôes cotidianas na EJA. Os jovens entraram definitivamente em cena com suas diferentes trajetórias escolares, com suas expectativas diversas em relação à escola e à modalidade, com suas formas específicas e variadas de ser jovem, com seus saberes, interesses e leituras de mundo particulares (Carrano, 2007; Medeiros, 2018; Nascimento, 2018). No que toca o interesse focal na pesquisa, os jovens instituem novas formas de tensionar a prática curricular desenvolvida pelos educadores. Se a EJA se torna majoritariamente dos jovens, modificando o cotidiano escolar e as relaçóes interpessoais, a pergunta central que a pesquisa enfrenta é: como uma educadora de Ciências desenvolve sua prática curricular na sala de aula da EJA, onde os jovens são agora a maioria? ${ }^{1}$

Destarte, a pesquisa se estrutura na interface do campo do Currículo e dos estudos acadêmicos sobre a EJA. As contribuições das teorias críticas, em especial as noções de currículo como prática (Sacristán, 2000) e de currículo como território de disputa (Arroyo, 2013), balizam nosso entendimento acerca do currículo como um constructo social e o professor como coautor de sua invenção (Goodson, 1997).

A construção de nosso contexto de inteligibilidade teórico-metodológico, por conseguinte, institui-se a partir da articulação desses referenciais, informada por pesquisas sobre as juventudes, enquanto o manejo metodológico foi produzido por meio do uso da história oral de vida e a pesquisa do tipo etnográfica. Nas tramas dessa tessitura, a investigação se realiza a partir dos seguintes questionamentos: em que medida as condições juvenis dos educandos da EJA qualificam a prática curricular da professora de Ciências? Entre os currículos prescritos e a realidade instituída pela presença dos jovens, quais desafios ela enfrenta? $\mathrm{Na}$ sua concepção, quem são os jovens da EJA? Quais conhecimentos escolares em Ciências a professora privilegia 
e quais estratégias desenvolve de forma a motivar os discentes e contribuir para sua presença nas aulas? Por meio dessas perguntas, confrontamos o processo complexo de fabricação curricular. Por um lado, é possível afirmar que o currículo é território de reprodução das desigualdades que estruturam nossa sociedade capitalista. É, contudo, central entender as contradições expressas no jogo que se estabelece entre os opressores e os oprimidos em afirmar ou deslegitimar determinados textos de saber. Exatamente nessa relação dialética interpelada pela presença dos jovens em sua sala de aula procuramos entender como uma professora de Ciências desenvolve suas práticas curriculares na EJA.

\section{AS JUVENTUDES DESAFIAM O CURRÍCULO E A DOCÊNCIA NA EJA}

Os estudos sobre as juventudes são centrais para refletir sobre o ato educativo na EJA, em especial no que se refere ao currículo. Eles precisam frequentar com maior fôlego os currículos de formação docente e suas práticas profissionais, abrindo-os ao debate sobre os educandos que estão na escola básica, em especial as juventudes pobres, negras e periféricas (Arroyo, 2017).

Cassab (2011) assinala três perspectivas hegemônicas que, em geral, informam as discussões sobre juventude: (i) a juventude como recorte etário, (ii) a juventude como período de transição e (iii) a juventude como devir. Marcar o trato sobre as juventudes nos limites de tais visóes é negar o entendimento de que não há apenas uma juventude, mas juventudes que se forjam a partir de diferentes pertencimentos de classe, gênero, raça, território, orientação sexual, entre outros. Em suma, é negar a constituição sócio-histórica das juventudes (Carrano, 2000; Cassab, 2011; Dayrell, 2007 e Sposito, 2003;).

Assim, se perspectivas do senso comum nos provocam a pensar a juventude como fase da vida, os estudos teóricos do campo sinalizam para a necessidade de superar tal visão e acentuar a constituição social e histórica da categoria jovem. Tal assunção desafia-nos a escrutinar os contextos de formação dos educadores de Ciências e Biologia, que, hegemonicamente centrados na aquisição dos saberes da área de referência, pouco interrogam sobre quem são os educandos jovens que estão na escola (Cassab, 2016). Marcados pelas epistemologias que centralizam sua formação nas Ciências Biológicas, tendem inclusive a produzir leituras acerca dos jovens a partir de discursos biologizantes e médicos.

Nesse campo de tensões, disputam no interior da escola tanto noçôes sobre a juventude que circulam no senso comum quanto aquelas que apostam em visões mais críticas e problematizadoras sobre essa categoria. Desconsiderar a complexidade do que é "ser jovem” é obliterar a noção de jovem como sujeito social, marcado pelas condiçôes tão desiguais que estruturam nossa sociedade e pelas diferenças que constituem suas identidades. Enquanto a escola se apoiar hegemonicamente na noção do jovem pobre problema desinteressado, testemunharemos os descompassos que ainda há entre a cultura escolar e as culturas juvenis e seus efeitos tão trágicos explicitados no enorme contingente de jovens fora da escola e na distorção idade-série que caracteriza o cenário educacional brasileiro, manifestada de forma ainda mais aguda na EJA.

A EJA, outrora vista como o lugar da satisfação profissional, especialmente por atender os adultos e idosos, hoje impõe desafios aos professores, que precisam enfrentar as tensões que se instauram a partir da presença massiva dos jovens na sala de aula. Não é incomum que as falas dos professores apontem para a aceitação dos alunos adultos e idosos, que se mostram esforçados, dispostos e que respeitam a hierarquia professor/aluno. Enquanto isso, os jovens não têm motivação, não realizam as tarefas propostas, falam demais e não prestam atenção (Carrano, 2007).

O que fazer, então? Para compreender, enfrentar e superar o descompasso entre a cultura escolar e as culturas juvenis, mudanças na práxis educativa se fazem necessárias. A escola é provocada a se ocupar da condição juvenil (Dayrell, 2007) e, nesse movimento, produzir inflexões radicais no currículo que pratica. Diante desse desafio, o estudo se propóe a investigar o trabalho curricular de uma educadora da EJA, que 
enfrenta na cotidianidade de suas aulas de Ciências as questões instituídas pela presença dos jovens. O nome fictício que iremos adotar para a educadora que tornou o estudo possível é Maria Aparecida. Sua experiência profissional na EJA e a disponibilidade em contribuir com a pesquisa justificam sua coparticipação em nosso estudo. Nosso empenho foi procurar entender as construçóes curriculares no contexto da disciplina escolar Ciências, por meio de um mergulho denso na história de sua vida e nas práticas curriculares que desenvolve.

Maria Aparecida é natural de Minas Gerais. Nasceu em Piau e lá viveu sua infância, adolescência e parte da juventude. Para Cida, esse foi um período de luta de seus pais para prover a família, mas também um tempo marcado pelo sentimento de afeto e felicidade. Seu pai, agricultor. Sua mãe, cantineira e professora leiga, alfabetizou-a em casa. Sua infância na escola do campo foi vivida de modo comum à maioria dos estudantes que mora na "roça” - madrugar e percorrer longos trajetos até a escola. Na sua família, ela foi uma das poucas que cursou o ensino superior. Aparecida se autodeclara parda e heterossexual. À época da pesquisa, estava com 44 anos e residia em Juiz de Fora (JF) há mais de 20 anos. Veio para JF para cursar o ensino médio, pois não havia escola em sua cidade. Uma experiência de reprovação no primeiro ano desse segmento a custou um ano de afastamento da escola, pois seu pai a impediu de retornar. Assim, sua trajetória escolar foi marcada por uma reprovação em Física e um ano evadida. Por intercessão da mãe, Cida pôde voltar a estudar no Centro de Estudos Supletivos, na intenção de recuperar o tempo perdido. Com o ensino médio finalizado, passou a ingressar em cursos preparatórios para o vestibular até ser aprovada e no ano de 2006, formou-se em Ciências Biológicas pelo Centro de Educação Superior (CES/JF). Havia certa expectativa de familiares que o curso escolhido fosse Pedagogia, mas ela insistiu no sonho de cursar Biologia. Para a educadora, foi uma escolha associada à proximidade com profissionais da saúde desde criança, já que sua casa era vizinha a uma unidade básica de saúde e pelo contato íntimo com a natureza que a vida na roça lhe proporcionou. Ela dividiu todo o seu tempo de formação na universidade com o trabalho e em 2005 começou a dar aulas na cidade de Piau, quando ainda não era graduada. Em JF, iniciou a docência em 2006, justamente em uma turma de EJA, porém sempre com contratos temporários.

Arroyo (2013) considera que é cada vez mais comum reconhecer proximidades entre os coletivos docentes e discentes com relação aos saberes, culturas, classe, raça, território e experiências vividas na escola. A breve história que contamos sobre Aparecida sinaliza nessa mesma direção. Cida inclusive afirma que muito de sua postura em relação aos jovens em sua sala de aula tem a ver com suas vivências pessoais marcadas pela dificuldade de frequentar a escola, o tempo afastada e a necessidade de trabalhar enquanto cursava a graduação.

Em suma, “o professor é uma pessoa; e uma parte importante da pessoa é professor” (1995, p.17), nos lembra Antônio Nóvoa. É nessa linha que a pesquisa se desafia a entender o entrelaçamento que há entre a história de vida da educadora e a produção do currículo de Ciências na EJA. Para isso, foi produzido um itinerário de pesquisa pavimentado a partir de autores do campo da teoria crítica de currículo e contribuiçóes de histórias de vida e dos estudos etnográficos na educação.

\section{A ESCRITA TEÓRICO-METODOLÓGICA DA PESQUISA}

A educadora da EJA constrói o currículo. Todo o potencial heurístico impresso nessa afirmação se efetiva quando a análise das criações criativas, resistentes e reprodutoras que os educadores produzem em suas práticas, dá-se mediatizada pela compreensão das condições concretas que conformam suas atuaçôes profissionais. Isto é, "o currículo não pode ser entendido à margem do contexto no qual se configura e tampouco independente das condiçôes que se desenvolve” (Sacristán, 2000, p.107).

Ainda assim, o professor não é mero objeto de arranjos curriculares produzidos em contextos alijados de sua prática, mas elemento de primeira ordem para a compreensão do que acontece nesse terreno contestado dos saberes, das práticas e das identidades que a escola legitima ou deslegitima (Sacristán, 2000). O currículo, por conseguinte, é um objeto de investigação aberto ao poder, à ideologia, à história. Não se materializa como o testemunho do que de melhor as ciências têm a oferecer às gerações futuras (Goodson, 
2008). Pelo contrário, é o terreno da disputa, que se configura entre a institucionalização da docilidade dos corpos e das leituras de mundo afeitas aos opressores e o anseio humano em ser mais (Freire, 1987). O estudo curricular, assim perspectivado pelas teorias críticas, impõe, portanto, a tarefa imprescindível de "questionar os conhecimentos tidos como necessários, inevitáveis, sagrados, confrontando-os com outras opçôes por outros mundos mais justos e igualitários, mais humano, menos segregadores dos coletivos que chegam às escolas públicas, sobretudo” (Arroyo, 2013, p.38).

Sacristán (2000, p.108) afirma que, "ordenar a distribuição do conhecimento através do sistema educativo é um modo não só de influir na cultura, mas também em toda a ordenação social e econômica da sociedade”. Arroyo e Sacristán, dessa forma, endossam o que é central ao pensamento freiriano: o ato educativo é sempre um ato político (Freire, 1987). Por isso, é urgente refletir e saber sobre o que e pelo que disputamos no território do currículo de Ciências, em um esforço de fazer da escola e da sala de aula espaços de afirmação dos educadores e dos educandos em toda sua condição humana, com suas histórias de exploração, dominação e também de luta e esperança. Implicar a docência em Ciências na EJA com a defesa dos direitos humanos, na linha em que advoga Arroyo (2017). Para tal, há de se escrutinar a dimensão do real que diz respeito à fabricação curricular docente, tensionada entre a identidade de um professor aulista e de um professor educador (Arroyo, 2013).

Nessa linha, entendemos a realidade do currículo de Ciências na EJA como resultado de interaçóes diversas que acenam desde o imediato que acontece na aula entre professora-conhecimento-educandos, até dimensóes relacionadas à atividade político-administrativa, a traduçôes do saber que recursos didáticos celebram e enquadramentos que processos avaliativos provocam. O currículo como cruzamento de práticas diversas atenta que muitos tipos de ações intervêm em sua configuração e que o processo ocorre mediante certas condições concretas. Destarte, Sacristán (2000) delimita o sistema curricular a partir da interação complexa de oito subsistemas. No limite dessa produção, destacamos quatro deles, que sustentam a análise realizada nesse texto.

i) Subsistema político-administrativo: é aquele que tem um alto poder de intervenção e definição do que acontece na escola. É uma instância de regulação que se concretiza através de intervençôes políticas e administrativas. No caso da pesquisa, essa influência se manifesta, por exemplo, pelo fato dos educadores da EJA do município de JF não pertencerem ao quadro de servidor permanente, já que não há lotação para a modalidade. A cada rodada de renovação dos contratos temporários, os professores correm o risco de serem alocados em uma nova escola, depondo contra a possibilidade de enraizamento em determinada comunidade escolar. Nesse subsistema, determinantes exteriores do currículo ficam bem evidentes, como as políticas educacionais formuladas pelos atores sociais que nele atuam, como por exemplo, o corpo técnico das secretarias de educação. No âmbito da análise que realizamos no estudo, destacamos a "Proposta Curricular: Educação de Jovens e Adultoo” (2012), formulada pela Secretaria de Educação de JF.

ii) Subsistema técnico-pedagógico: é composto por formadores de professores, especialistas e pesquisadores em educação. Cria linguagens e tradiçôes, produz conceitos, sistematiza informações e conhecimentos, propóe modelos, sugere esquemas de ordenação de práticas que incide na política, na administração, nos professores, etc. Tem um peso que varia dentro dos diferentes níveis e modalidades educacionais.

iii) Subsistema de produção de meios: Diz respeito principalmente à produção de materiais didáticos diversos baseados nos currículos prescritos. Esses meios não são instrumentos neutros que traduzem as prescriçóes curriculares, mas exercem forte controle sobre o fazer docente. Além disso, lógicas mercadológicas perpassam esse sistema, que também criam dinâmicas que incidem fortemente sobre a prática pedagógica. A EJA historicamente carece de recursos didáticos próprios e diversificados, portanto sofre menos com a mercantilização. Assim, os currículos da EJA não são tão estabilizados, como se constata no caso da disciplina Ciências, realizada no ensino dito regular. Para alguns professores, essa realidade curricular na EJA aponta para a possibilidade de maior exer- 
cício de sua autonomia, ao mesmo tempo em que a falta de suporte material é objeto de desagravo e reivindicação, em especial se considerada a formação lacunar específica para a modalidade e a jornada excessiva enfrentada por seus educadores. Contudo, é importante observar que o livro didático do ensino dito regular costuma ser uma fonte acionada pelos professores da modalidade.

iv) Subsistema prático-pedagógico: diz respeito às relações entre professores e alunos no que comumente chamamos de ensino. É onde se fazem realidade as propostas curriculares, que são "condicionadas pelo campo institucional organizativo imediato e pelas influências dos subsistemas anteriores" (Sacristán, 2000, p.26).

Em seu conjunto, esses ordenamentos dão materialidade ao currículo, ao mesmo tempo em que são por este afetados. Eles nos provocam a pensar o currículo não só como um corpo de conhecimentos, mas ao mesmo tempo como uma dispersa e encadeada organização social (Sacristán, 2000). Nesse sentido, apesar da defesa da autonomia docente ser um marcador fundamental da pesquisa, reconhecemos que essa se realiza condicionada pelos diferentes subsistemas supracitados. Saber disso não é reduzir a profissão docente a de meros técnicos. É, na verdade, munir-nos contra interpretaçóes que ora responsabilizam os professores pelo que acontece na escola e ora atribuem apenas à sua disposição pessoal o caminho para a produção de currículos sintonizados com a realidade vivida pelos educandos jovens da EJA.

Em suma, o estudo construiu um itinerário teórico-metodológico comprometido em reconhecer o currículo como um campo prático, o que significa entendê-lo como um território onde práticas diversas se interseccionam, e não apenas práticas pedagógicas no âmbito das interações e comunicações educativas. A investigação preocupa-se em entender o saber-fazer docente, situado na prática de sua ação pedagógica e na prática dos subsistemas que conformam a fabricação curricular. Por fim, a centralidade que o professor assume no processo de construção curricular faz com que o estudo invista em um caminho metodológico forjado na articulação entre a história oral de vida e a abordagem etnográfica em educação.

O método etnográfico é um modo de fazer pesquisa qualitativa próprio da Antropologia, que há algumas décadas tem sido apropriado pelo campo educacional (André, 1995). Enquanto na Antropologia seu propósito central é compreender a ação de um grupo no âmbito de seu sistema social e cultural, o interesse focal dos estudiosos da educação é com o processo educativo. Dessa forma, conforme assevera Marli André (1995), certos requisitos da etnografia não precisam ser atendidos plenamente nos estudos em educação, como o tempo prolongado do campo. Daí a diferenciação que a autora faz entre a etnografia stricto sensu, que se realiza na área da Antropologia, e a de tipo etnográfico, na educação.

Com base em autores como Kutter (2010) e Mattos e Castro, (2011), sublinhamos no estudo as contribuiçôes que a pesquisa de tipo etnográfico promovem: (i) realizar uma pesquisa de campo no local em que a professora realiza seu exercício profissional; (ii) produzir observaçôes, registros e interpretaçôes com base no contato direto, frequente e mais prolongado com a professora no contexto em que produz suas práticas curriculares e (iii) tornar estranho o ambiente tão familiar da escola, na intenção de compreender o complexo processo de fabricação curricular de forma contextual.

A observação com inspiração etnográfica aconteceu na escola municipal em que Aparecida atuava na EJA desde 2015. Contou com o endosso da direção da escola e dos alunos da EJA. Depois da pesquisadora e da investigação serem apresentadas, rapidamente os educandos acostumaram-se com a postura silenciosa e atenta da pesquisadora em sala, ocupada em observar a ação da professora e fazer registros escritos em seu caderno de campo. Desse modo, a oportunidade de estar na sala de aula por tempo prolongado propiciou testemunhar no cotidiano da vida escolar as escolhas curriculares que a educadora realizava diante dos jovens e as questôes e atitudes imediatas do dia a dia.

Foram feitas observações das aulas de Ciências em duas turmas do ensino fundamental II, ao longo dos meses de agosto a dezembro de 2018. As turmas eram bisseriadas, isto é, cada turma atendia concomitan- 
temente alunos inscritos em duas fases de ensino, fases V/VI e VII/VIII, respectivamente. ${ }^{2}$ Cada turma tinha em média 20 alunos, mas a frequência era muito flutuante. As duas turmas eram compostas na maior parte por adolescentes e jovens adultos. Grande parte dos alunos era negra. Todos pobres e moradores do bairro periférico que a escola está localizada ou do seu entorno.

No que toca à história oral de vida, esta foi escolhida pela possibilidade de compreender as práticas curriculares na tessitura da própria vida de quem a produz e dá sentido a ela. Seu manejo permite desvelar a relação dialética entre o sujeito e o social, na medida em que proporciona o entendimento de como a vida particular de uma professora remete-se às práticas sociais e às formas singulares com que cada ator social se insere e atua no mundo (Meihy e Holanda, 2007).

$\mathrm{Na}$ escolha intensiva de produzir narrativas de caráter biográfico, também é possível estreitar os laços de confiança e troca entre pesquisadora e professora. Nessa direção, a história de vida leva em conta um conjunto de procedimentos articulados entre si para registrar narrativas de experiências humanas, tais como o local, o tempo de duração e a transcrição das entrevistas (Meihy e Holanda, 2007). A intenção é "tomar a experiência humana como objeto de conhecimento, passível de mensuração, análise e interpretação" (Silva e Maia, 2010, p. 4). Da estória de si contada, buscar as relaçóes com os contextos sociais, culturais, econômicos e políticos que marcam a constituição da pessoa e do seu exercício profissional (Goodson, 2015; Sousa e Cabral, 2015) e, nesse movimento, entender as escritas das práticas curriculares nas aulas de Ciências da EJA.

Para as entrevistas de história oral de vida, foram organizados sete encontros que aconteceram na casa da professora. Os encontros seguiram um roteiro semiestruturado, previamente construído, centrado em aspectos da vida pessoal e profissional que entendermos afetar a prática curricular. As temáticas abordadas foram: 1) família, tempos de infância, adolescência e juventude; 2) tempos da escola; 3) escolha pelo curso de Ciências Biológicas e os tempos de formação docente; 4) trajetória profissional; 5) a EJA; 6) construçóes curriculares na EJA e 7) construçôes curriculares na EJA em face do educando jovem. Todas as entrevistas foram gravadas e transcritas. Assim, o arquivo da pesquisa foi produzido com base nos depoimentos de história de vida e os registros do caderno de campo. A análise interpretativa se deu a partir do cruzamento dessas fontes.

\section{PRESCRIÇÕES CURRICULARES E O CURRÍCULO EM AÇÃO: OS JOVENS EM SUSPEIÇÃO}

Para compreendermos como se dá a prática curricular de Aparecida mediante a presença marcante dos jovens em sua sala de aula, não basta interpelar determinada configuração estática que se apresenta em um dado momento da ação. É imperioso interpelá-la na construção interna, na qual convergem de forma não linear e hierárquica as influências dos diferentes âmbitos que definem o sistema curricular, conforme assinala Sacristán (2000). Ainda que um conjunto de pesquisas aponte que não há coincidência entre as prescriçốes curriculares e o que os professores e educandos realizam na sala de aula, não é possível desconsiderar que o currículo prescrito se move no sentido de buscar enquadrar como deve se dar a prática no ensino (Sacristán, 2000). Ele define princípios pedagógicos, conteúdos e códigos considerados legítimos para o processo de escolarização e ordena a ação. A força de sua influência inclusive se manifesta na expressão de outros âmbitos que conformam o sistema curricular, como a produção dos recursos didáticos e o controle que se produz por meio dos processos avaliativos. A importância do currículo prescrito é evocada na análise quando destacamos duas de suas expressóes importantes: a política curricular da EJA no município de JF e o livro didático.

A Proposta Curricular (2012) é o documento que rege a modalidade na rede municipal de educação, onde atua a docente. Segundo a proposta, a organização que se sugere para EJA persegue a flexibilização curricular e a autonomia docente. $\mathrm{O}$ documento propõe a adoção de cinco eixos temáticos integradores como forma de assegurar a especificidade de cada componente curricular, integrando-o a um todo significativo. Em 
consonância com documentos nacionais elaborados pelo governo federal (Brasil, 2000, 2002), a proposta sublinha para os currículos da EJA a questão da integração das áreas de saber, tendo a noção de "cidadania" como o elemento integrador dos saberes e das práticas realizados na modalidade. $\mathrm{O}$ documento ainda defende práticas de letramento ao longo de todo o curso educacional e como tarefa de todos os educadores. Ainda em consonância com os documentos nacionais, o texto consolida os saberes e as vivências dos educandos da EJA e a questão do trabalho e das tecnologias como componentes centrais na concretização dos eixos temáticos.

É um avanço o município possuir um documento próprio para a EJA, que ressalta pontos importantes para o trabalho na modalidade. Entretanto, a proposta não enfrenta o debate acerca de quem são os educandos da EJA em seus pertencimentos de classe, raça, gênero, território e etário, entre outros, e nem ao menos sugere o debate acerca das juventudes. Ela assinala que é preciso considerar nas construçóes curriculares quem são os educandos da EJA, todavia, o debate é genérico e não disserta sobre os desafios que os professores enfrentam em assumir de forma determinante as condições juvenis dos educandos na produção curricular. Outro ponto destacado é a ausência de propostas curriculares específicas para cada área de conhecimento. A orientação é que o documento curricular produzido para o ensino das áreas disciplinares no ensino dito regular deva regular o trabalho na EJA. Em síntese, o sujeito jovem não é quem centraliza as diretrizes curriculares formuladas, por conseguinte, não será nesse documento que Cida encontrará respaldo para forjar práticas curriculares em Ciências que dialoguem com seus alunos jovens da modalidade.

Aparecida afirma conhecer a Proposta, mas confirma que nunca participou de seu estudo coletivo em qualquer escola do município que já atuou. Não a adota como referência de sua prática curricular, com base na alegação de que não se sente segura para trabalhar com a organização curricular por eixos. Sua indisposição é determinada pela ausência de uma orientação coletiva praticada por toda a equipe da escola e por reconhecer que sua formação não atende ao propósito do trabalho interdisciplinar. Diz a professora: "não temos preparação para trabalhar dessa forma. Somos preparados para trabalhar cada um no seu individualismo”.

Os efeitos do subsistema técnico pedagógico (Sacristán, 2000) não são os únicos que Aparecida reconhece como definidores de sua prática curricular apartada do que propóe a política curricular para EJA no município. A ação manifesta do subsistema político administrativo se destaca, na medida em que institui formas de recrutamento e condiçóes para o trabalho docente responsáveis por produzir rotinas na escola, marcadas pela dificuldade de encontro entre os profissionais da educação que atuam na modalidade, por sua grande rotatividade por conta de como se dá o processo de designação dos docentes com contratos temporários e pela dificuldade em construir parcerias de trabalho com professores de outras áreas. Na entrevista, Aparecida até menciona uma atividade pedagógica desenvolvida com a professora de língua portuguesa, que aliou o estudo de plantas medicinais à discussão sobre gêneros textuais. Não obstante, essa é a exceção e não a regra que caracteriza o trabalho curricular desenvolvido. Durante a pesquisa de campo na escola, não foi possível constatar nenhuma outra prática curricular dessa natureza.

Assim, a interdisciplinaridade é valorada no discurso da professora, mas não por atender especificamente às demandas dos jovens educandos ou por ser algo que pratica em suas aulas. Para Aparecida, a formação docente, a forma disciplinar que a escola se estrutura e as próprias condiçóes precárias do exercício profissional são obstáculos para sua efetivação no contexto das práticas curriculares que ela desenvolve com os jovens.

É o reconhecimento da necessidade de atender às dificuldades de leitura, interpretação e escrita dos jovens, de desinteresse pelas ciências e desmotivação ao estudo que afeta a prática curricular da professora no intento de se aproximar dos educandos. Tais desafios póem em contestação os conteúdos selecionados, exigindo da professora mais atenção aos processos de letramento do que aos conteúdos em Ciências propriamente ditos. Assim, ela assume nas aulas a responsabilidade de trabalhar o texto, de ler em voz alta, de fazer correçốes de sintaxe, ainda que reconheça os limites de sua formação. Diz a professora: 
Muitas das vezes não adiantava eu ficar trabalhando, batendo em cima do conteúdo se o aluno não sabe escrever. Se ele não sabe ler aquele mínimo que ele escreveu ali [...]. Não que eu seja professora alfabetizadora, não sou, mas o que eu posso fazer para contribuir?

Nossa interpretação indica que as práticas curriculares que a professora desenvolve mais tangenciam aspectos relevantes no documento da política do que reestruturam sua ação. As prescrições curriculares têm menor valor para articular sua prática do que as experiências acumuladas ao longo de sua trajetória pessoal e profissional. Sacristán (2000) argumenta que para os professores, não é uma tarefa trivial passar de princípios ideais orientadores de determinada prática pedagógica para a ação efetiva coerente com tais parâmetros. Daí a importância de meios estruturantes do currículo, como o livro didático.

Por conta de motivos diversos, o autor nos fala da pouca operatividade das políticas curriculares na produção do currículo em ação, do exílio dos professores e de suas experiências inovadoras nos contextos de produção das políticas, da complexidade da realidade escolar diante de prescrições genéricas ou pormenorizadas, incapazes de dar conta das tensões e dilemas próprios do ato educativo e do regime de trabalho excessivo do professorado. Em suma, uma realidade que expóe a exigência de se apresentar aos professores as prescriçóes formuladas no âmbito político-administrativo. Por conseguinte, como pondera Sacristán (2000), o subsistema de produção de meios elabora recursos, como os livros didáticos, que procuram interpretar e traduzir para os professores sobre o que tratam as políticas, seus conteúdos e significados. Tais recursos incidem com força na prática pedagógica. Isso é possível notar no contexto das práticas curriculares desenvolvidas pela educadora.

Aparecida utiliza o livro didático EJA Moderna (2014), ${ }^{3}$ adotado na escola, como importante apoio para seu planejamento curricular. Temas presentes no livro como "água, saúde e saneamento básico" e "prática de atividades físicas" frequentaram suas aulas nas fases V e VI, enquanto a temática "vacinação no Brasil” e "doenças infecciosas e parasitárias” foram abordadas nas fases VII e VIII. Todavia, para que os conteúdos selecionados pelos livros didáticos frequentem sua aula, é preciso que sejam validados pelo grau de afinidade que a docente tem com determinada temática, pelos interesses manifestos pelos educandos e pelo cruzamento que estabelece com outros livros didáticos do ensino dito regular, que ela coleciona ao longo de sua trajetória profissional.

A partir do questionamento de um educando jovem sobre a possibilidade de se hidratar apenas com Coca-Cola, a aula sobre água, por exemplo, tomou outro rumo daquele sugerido no livro. No dia seguinte, a professora levou a turma para sala de multimeios da escola. Lá projetou dois vídeos curtos e trabalhou com rótulos da Coca-Cola, de suco industrializado e água mineral, a fim de debater os efeitos do consumo excessivo de açúcar à saúde humana. Isso significa que o livro didático influi na modelagem curricular, mas depende de seu trabalho autoral de seleção curricular para que as práticas curriculares desenvolvidas atendam os interesses dos jovens.

Enquanto a política curricular formulada pela Secretaria de Educação não se propôe em prescrever conteúdos específicos para as aulas de Ciências, nos livros a professora encontra uma listagem que é considerada na construção do currículo em ação, testemunhando, por conseguinte, uma maior influência desse currículo prescrito na configuração curricular. Conforme visto a partir do exemplo evocado, os livros didáticos funcionam na aula da professora Aparecida como uma diretriz organizativa, mas sua prática não se restringe à sua influência.

Arroyo (2013) é categórico ao afirmar que os professores não encontram apoio nas políticas educativas, curriculares e no material didático para enfrentar as condiçóes do triste viver dos educandos e a tarefa de educá-los. Mas se o currículo prescrito não auxilia a professora na aproximação à vida e aos interesses dos educandos, qual força a impele em direção aos jovens?

\section{COMO A PROFESSORA MODELA O CURRÍCULO?}

“É impossível separar o eu profissional do eu pessoal” (Nóvoa, 1995, p.17). Esse é o aforisma que define um princípio central da pesquisa. Isso significa que a partir do momento em que o currículo é apresen- 
tado aos professores, esses atores sociais o modelam, enquadrados em certas margens que definem possibilidades e limites para a sua ação. A prática docente está prefigurada dentro do campo em que atua, por razôes de ordem administrativa, política, de vida e formação e da própria cultura escolar. Em suma, "a autonomia sempre existe, mas suas fronteiras também” (Sacristán, 2000, p.168).

Assumimos que o trabalho curricular realizado por cada professor se manifesta também em uma relação íntima com sua maneira de ser e sua história (Goodson, 2015). A prática de Cida está permeada pela história de sua vida. É possível, por exemplo, perceber relações entre a ênfase que ela dá em suas aulas na EJA aos conteúdos sobre saúde e à importância que profissionais dessa área exerceram no tempo de sua infância e juventude. Ainda que a atividade curricular da professora se estruture e assuma concretude dentro do quadro de condicionantes da prática, há “importantes margens de autonomia na modelação do que será o currículo na realidade” (Sacristán, 2000, p.149).

A formação profissional é outra margem importante para entendermos a ação da educadora, aprofundada no que toca à apropriação dos conteúdos científicos de sua área de conhecimento e lacunar no debate específico da modalidade e dos jovens educandos. Aparecida pondera que "na graduação, nenhum momento tratou da EJA". Também não se deteve em reflexões sobre quem são os educandos que frequentam a escola da EJA, especialmente no tocante à sua condição juvenil.

Esse conflito entre o que a formação inicial tende a privilegiar e os desafios que o professor experimenta no curso da sua prática faz com que os docentes ressignifiquem sua formação diante da necessidade de atender os propósitos profissionais que elegem no seu trabalho (Tardif, 2009). A professora percebe ao longo de sua prática que a formação inicial pouco dá conta da problemática de superar o aluno genérico. Ela reconhece que marcam sua práxis docente o fato de ter sido uma estudante trabalhadora e a influência de sua mãe, que mesmo sem formação, alfabetizava e estava sempre preocupada com o outro. Porém, é o exercício profissional na EJA com os jovens que afeta intensamente sua docência. Aparecida afirma:

Eu tive que aprender. Eu coloquei isso na minha cabeça. Tem professor que chega e vê uma sala de meninos indisciplinados e quer colocar aqueles meninos do jeito que ele quer. Aí eu aprendi, lá nessa escola mesmo - foi onde eu aprendi muito -, que ali é o lugar deles. Eles estão no ambiente deles. $\mathrm{O}$ estranho ali sou eu. A estranha sou eu. São as Ciências. Eu que vou ter que me adaptar a eles.

Assim, sua identidade como professora de Ciências é remodelada paulatinamente no exercício cotidiano da docência na EJA. É nessa direção que assevera Arroyo (2013), ao afirmar que a prática docente é inseparável da história humana e social dos educandos. O professor entende o seu of ício na medida em que tenta enxergar e entender seus alunos. Isso implica reposicionar as relaçôes que estabelece com os educandos reais, requalificar os conteúdos considerados necessários, reinventar práticas que favoreçam a aprendizagem e, mesmo antes disso, que garantam a presença e frequência do jovem em sua sala de aula. Para Cida, é a escola que tem que enfrentar o desafio de se rever para acolher os jovens e não, conforme assevera Arroyo (2007), buscar conformá-los a modelos que o aluno pobre, periférico, trabalhador terá enorme dificuldade de atender. Um propósito bastante complexo.

Se no início em que a lousa dominava o tempo da aula a relação era de insegurança e desconfiança com seus educandos, adiante Cida percebe que é possível e necessário mobilizar recursos didáticos diversos como imagens, textos, vídeos e exercícios; explorar com os educandos outros espaços da escola e elevar seus interesses pela aula através do diálogo, da abordagem de questôes afins ao seu cotidiano; produzir oportunidades diversas de avaliação que inclusive estão atentas às contingências que marcam a vida do educando da EJA e que os impedem de frequentar a aula cotidianamente. A infrequência, a evasão, as consequências que a experiência da reprovação produz são dimensões que interpelam a fabricação curricular de Cida.

À vista disso, é fundamental buscar compreender os fatores que impelem os educandos para fora da escola ou afetam suas presenças regulares em sala de aula. No que toca à escola, é pertinente considerar a inadequação do currículo diante da vida concreta e sofrida dos educandos jovens da EJA (Arroyo, 2017). Já os 
processos econômicos, sociais, culturais e políticos que definem nossa sociedade capitalista produzem uma série de fatores externos que os tensionam para fora da escola: a necessidade de trabalhar, de ajudar nos afazeres domésticos e no cuidado de outros membros da família, a urgência de assistir um doente, o machismo que interdita a ida à escola - especialmente às mulheres depois do casamento ou da maternidade -, a gravidez precoce, a distância da escola, o envolvimento com o crime, a violência, entre outros (Nascimento, 2018). "Qual EJA se configurar para esse tipo de vulnerabilidade de formas de viver?” (Arroyo, 2007, p. 04) é uma provocativa que Cida parece enfrentar e que se aprofunda na medida em que ganha experiência na modalidade.

No decurso de sua prática profissional, Aparecida interpela a rigidez de sua formação, do currículo de Ciências prescrito e da própria cultura escolar que, ao idealizar o estudante com base em disposiçóes meramente escolares, favorece a construção de leituras hegemonicamente negativas dos jovens que estão na EJA. Ela se movimenta do compromisso com determinados conteúdos relevantes per se para apreciar os jovens como desafio à sua docência na modalidade. Contudo, esse é um movimento difícil de se realizar.

Quando Aparecida iniciou a regência em turmas de EJA, em 2006, a presença dos jovens ainda não era hegemônica. Esse tempo foi marcado pela satisfação profissional de trabalhar com adultos e idosos interessados, determinados e cordeiros, ainda que sofridos pela dureza de suas vidas. Em 2014, quando volta a assumir a regência na modalidade, depara-se com outra realidade e o sentimento que experimenta é de decepção com essa "nova EJA". Ela diz ter levado um choque ao reconhecer rostos tão jovens. Percebeu ali o grande desafio que tinha pela frente.

A decepção e o fato dos jovens não serem bem-vistos também dentro da sala de aula da modalidade são questóes que todo educador precisa lidar caso intencione forjar sua prática curricular em sintonia às juventudes da EJA (Arroyo, 2007). Assim, a presença das juventudes na EJA exige de Aparecida o aprendizado de como exercer uma docência renovada na modalidade. A humanização de um coletivo bateu em sua porta e ela abriu, é o que podemos perceber quando afirma: "Eu aprendi sendo professora da EJA que eu tinha que ser flexível. Bem flexível. Humana. Que não adiantava colocar uma barreira entre mim e os alunos, que não ia funcionar”. Essa flexibilidade acaba incidindo sobre a forma que opera a seleção curricular. Quanto mais se aproxima do educando, mais uma listagem enciclopédica de conteúdos é contestada.

Para Aparecida, a presença dos jovens em sua sala de aula é algo desafiante e que exige aprendizagem. Ela considera a juventude um momento de grandes transformaçóes e, portanto, de grandes conflitos. A escola, por ser um espaço por excelência do encontro e da interação, é tensionada a lidar com esses conflitos diariamente. Aparecida admite ainda que, em geral, é difícil despertar o interesse dos jovens pelas Ciências. Em um primeiro momento, ela parece operar a partir de perspectivas limitadas acerca da juventude, conforme assinala Cassab (2011).

Todavia, ao ser questionada sobre a sua visão acerca dos jovens da EJA, fica evidente que na docência ela aprende a reconhecer a complexidade que envolve qualificar as juventudes de forma homogeneizante e uníssona. As narrativas que produz evidenciam contradiçôes e ambiguidades na forma como os qualifica. Ela diz que há vários tipos de jovens: questionadores ou mais passivos, interessados pelo conteúdo escolar e compromissados com as tarefas ou mais reativos à importância da escola. Na sua apreensão, entende que para alguns não há muita expectativa com a função da escola socializadora de conhecimentos sistematizados. Para eles, a escola é fundamentalmente um espaço de encontro e socialização, enquanto outros esperam mais. Estes pensam em prosseguir com os estudos e associam o sucesso escolar à possibilidade de ocuparem melhores postos no mundo do trabalho.

Sua vivência na EJA também a faz refletir sobre o quanto determinadas características atribuídas ou desejadas aos jovens da EJA não são inatas, mas relacionam-se com suas experiências sociais. Se um jovem não é questionador, isso tem a ver com o fato de grande parte desses estudantes não ter acesso a bens culturais e inclusive à própria cidade. A maioria circula apenas em seus bairros de moradia ou fazem incursóes rápidas ao centro da cidade. Cultura e territórios diversos da cidade, em especial aqueles em que moram os grupos de maior poder aquisitivo, são interditados aos jovens da EJA e isso marca suas existências. 
Aparecida fala também de outras constituições identitárias de seus jovens alunos. Reconhece que são em sua maioria negros e pobres. Muitos apresentam trajetórias consideradas de indisciplina e reprovação no dito regular. A EJA acaba sendo o lugar e o tempo que é possível enxergá-los além de pretensas disposiçôes escolares, diferente do que acontece no ensino dito regular, enxergá-los no sentido mais pleno de suas vidas. É isso que Aparecida pondera em sua fala:

Eu os vejo a princípio como um desafio, mas depois passa a ser um aprendizado conviver com eles, a lidar. Você vai aprendendo a enxergar, a visualizar um pouco a realidade de cada um. De onde veio. Qual é a sua história de vida. Muitas vezes, lá no regular, não enxergamos suas histórias. São meramente alunos e pronto acabou. Tem que estudar, passar, tirar notas boas nas atividades. Ali, na EJA, a gente acaba descobrindo a história de vida de cada um.

À vista disso, é uma preocupação constante no exercício de sua prática docente questionar como atender o aluno de forma a garantir sua permanência na escola e o término de seus estudos. Algumas estratégias são preferencialmente adotadas pela professora, como adicionar ao planejamento temas levantados pelos próprios educandos, tais como suicídio, meio ambiente, alimentação, sexualidade, gravidez na adolescência e drogas. Todavia, Aparecida assinala que a possibilidade de atender os temas indicados pelos próprios educandos está condicionada à conquista da sua confiança e do seu interesse, já que nem sempre eles se posicionam sobre o que é abordado em aula, visto que a desatenção e o desinteresse se sobressaem. Percebemos nas observações da escola que na turma mais participativa, os interesses dos educandos eram regularmente explicitados no próprio turno do diálogo provocado pela discussão da aula. Na turma menos participativa, a professora procurava estimular que os educandos indicassem quais temas gostariam de discutir, na intenção de buscar construir a aula seguinte com base em suas considerações. Em ambos os casos, notamos a docente aberta para que os interesses manifestos afetassem o planejamento realizado, mas o diálogo não é algo que está dado na sala de aula, é uma conquista, que envolve outras estratégias, conforme as inventariadas no decurso das observações etnográficas realizadas, a saber: (i) dedicar tempo da aula para que os educandos falem de si, de suas experiências de seus interesses; (ii) submeter os conteúdos em Ciências a critérios de validação que passam pelo o que acontece no tempo presente da aula. Um exemplo observado foi o debate sobre a dengue, visto que a cidade enfrentava um aumento significativo de casos notificados; (iii) questionar regularmente os alunos, fazer muitas perguntas, apelar para que opinem e expressem suas leituras pessoais sobre assunto; (iv) buscar realizar metodologias mais ativas que invistam no protagonismo discente, como dinâmicas de grupo; (v) investir sempre na afirmação da autoestima do educando - elogiar, estimular a participação - e, por fim, (vi) estimular que os educandos se ajudem entre si. Isto é, apostar na capacidade que cada um tem de contribuir na aprendizagem do outro.

Em suma, o aluno está lá a disputar terreno no espaço sagrado do currículo. Mas o quanto especificamente sua condição juvenil é focada? Quando questionada diretamente se a condição juvenil dos educandos exerce uma pressão curricular determinante na escolha dos conhecimentos escolares, a professora rejeita essa presunção. A argumentação que ela produz sobre essa problemática defende a relevância dos conteúdos que aborda em aula para qualquer faixa etária. Ela sugere que há um repertório de saber de excelência que merece menção no contexto da disciplina escolar Ciências, independente de quem são os sujeitos da relação pedagógica. Dependendo do aluno da EJA em questão, o conteúdo atende uma finalidade específica. O centro de sua preocupação se refere mais à questão da apropriação dos conhecimentos e da progressão do educando, o que explica duas outras estratégias adotadas: (i) a de diversificar, na medida do possível, os materiais didáticos utilizados em sala - textos xerocados, charges, figuras, vídeos, trechos do livro didático - e (ii) a de realizar várias atividades avaliativas distribuídas ao longo do semestre, ao invés de avaliaçôes mais estanques e muito valoradas.

Arroyo nos provoca a entender a estabilidade curricular e a defesa de conteúdos canônicos da biologia na prática docente.

Como não ser fiel a conteúdos que aprendemos a cultuar como sagrados? Nada fácil aos docentes das escolas ter uma postura crítica e tentar desconstruir, desordenar os conteúdos de sua matéria nem em função 
da aprendizagem dos educandos. Os ordenamentos curriculares carregam um caráter de necessidade e inevitabilidade que nem se cogita desconstruir e recriar esse conhecimento sacralizado (Arroyo, 2013, p.46).

Suas considerações anunciam os limites de se entender o currículo em ação em uma análise reduzida da interação entre professores e alunos, de onde se procura deduzir modelos qualificados ou inadequados de atuação. Em suma, as aulas são microssistemas educativos onde acontece um "fluxo mutante de acontecimentos" (Sacristán, 2000, p. 205).

Apesar da sala de aula ser um ambiente pluridimensional, onde acontecimentos simultâneos e imprevisíveis acontecem e, a despeito das estratégias inventariadas acima que Aparecida faz emprego no curso das práticas curriculares que desenvolve, é reconhecida certa estabilidade dos estilos docentes. Qualquer pessoa que entra em uma sala de aula a reconhece não apenas fisicamente, mas reconhece toda a sua dinâmica, incluindo a dinâmica professor-conhecimento-aluno e as atividades previstas, ou seja, a prática docente. Nesse sentido, a aula de Ciências em uma EJA cada vez mais jovem tende a se assemelhar a qualquer outra, pois esquemas práticos, como as tarefas escolares formais, regulam e tipificam as práticas docentes. Estas dizem respeito ao que se pensa e estrutura como finalidade própria da escola e do currículo (Sacristán, 2000). O curso da ação não é espontâneo, ele vem carregado de marcas da estrutura, configurado em um plano interno, onde as próprias práticas geram padróes de comportamento nos professores. Todavia, a EJA, na radicalidade do entendimento de suas especificidades em relação ao ensino dito regular, afirma a necessidade de conformar o currículo às experiências de vida e existências dos seus educandos. Isso implica enfrentar nas práticas curriculares em Ciências na EJA uma série de questionamentos potentes que Arroyo (2007, p. 6) formula:

Aqui cabe esta pergunta que não é fácil de responder, mas que teremos de colocar com toda força: que saberes aprende um adolescente, um jovem e um adulto que passa anos e anos nesses processos de sobrevivência tão instáveis? O que ele se pergunta sobre a vida, sobre a natureza, sobre a sociedade, sobre o trabalho, sobre a família, sobre a sua condição como homem, como mulher? Às vezes é pai ou mãe de dois filhos, três filhos, mãe. Que interrogações ele se faz? Como deixar que aflorem essas indagaçôes, para organizá-las e trabalhá-las nos currículos?

Problemáticas que Aparecida tateia com limites, na medida em que experiencia as dificuldades de produzir seleçôes curriculares que tragam para o centro do diálogo os sujeitos, seja o jovem negro e pobre da EJA ou mesmo sua própria história de vida. No tempo da observação de suas aulas, em nenhum momento a professora fala de si e de sua própria trajetória como tática para se aproximar dos educandos.

Isto não é algo incidental, a prática curricular de Aparecida é marcada pela estrutura, também segue um padrão pedagógico e, por isso, as tarefas da ação se assemelham às tarefas realizadas em qualquer outra aula, mesmo diante do esforço de conquistar seus alunos. O padrão pedagógico não se refere apenas ao método, mas também em relação aos conteúdos selecionados. É nessa relação com a seleção dos conteúdos que a disciplina escolar acaba por se configurar ainda muito impermeável às singularidades da EJA, como por exemplo, a definição da categoria trabalho como um princípio estruturante do currículo e a presença hegemônica de jovens negros na aula. Conteúdos canônicos ainda são eleitos, em detrimento de temáticas outras que poderiam ampliar a leitura de si, do outro e do mundo dos jovens da EJA.

Em suma, estabilidade e mudança, reprodução e inovação curricular convivem e disputam hegemonia. Por isso, apesar de constatarmos que existe certa estabilidade da prática docente, a pesquisa indica que o cotidiano da sala e o percurso que a professora faz ao longo da carreira contribuem para que ela ensaie reaçôes, na tentativa de fazer do ensino de Ciências algo contextualizado e significativo para esses alunos, com histórias de vida marcadas pela opressão e exploração. Percebemos que com a experiência adquirida ao longo dos anos de trabalho, Aparecida desenvolve maneiras distintas de fazer com o que os alunos aprendam, aumenta seu repertório de tarefas, ganha confiança em si e nos alunos. Repensa o que deve ser ensinado e como. No terreno dessas contradiçôes, a educadora produz dialeticamente suas práticas curriculares na EJA. 


\section{ÚLTIMAS PALAVRAS}

A EJA vive um processo de juvenilização que exige o questionamento de como a modalidade e especificamente a prática docente têm se conformado diante dessa nova realidade. Esse é um desafio incontornável diante da tarefa de questionar e desconstruir arquiteturas curriculares rígidas, abstratas, conteudistas e cientifizadas na modalidade, que acabam por interditar o diálogo entre a leitura de mundo de seus educandos e os conhecimentos escolares em Ciências.

Vimos que os currículos prescritos não se organizam em torno das juventudes, enquanto as análises das práticas curriculares no âmbito prático-pedagógico revelam movimentos contraditórios do fazer docente. Ao mesmo tempo em que há semelhanças a qualquer aula de Ciências, a professora, mobilizada pelo entendimento de que é preciso garantir a presença dos educandos e sua disposição pela matéria, busca celebrar seus interesses no plano de definição curricular. Nesse movimento, ela elege em especial temas relacionados à Educação em Saúde e à Educação Ambiental.

O atendimento das singularidades de seus alunos não se restringe apenas à questão da seleção dos conteúdos, já que na maior parte do tempo, a principal distinção que há em relação às prescriçôes curriculares estabilizadas na disciplina escolar Ciências do ensino dito regular diz respeito à quantidade de conteúdos tratados na EJA. O empenho da docente se materializa também por meio da produção de recursos textuais que considerem as dificuldades discentes de leitura e interpretação e pelo emprego de outras metodologias que não apenas a expositiva. Assim, a professora mobiliza recursos didáticos diversos, como imagens, textos, charges e vídeos. Ela explora outros espaços da escola, como a sala de multimeios e eleva o interesse de seus alunos pela aula através do diálogo e a escuta de suas vidas. O diálogo é algo que ela busca conquistar, mas reconhece o quanto é difícil instituí-lo no cotidiano das aulas. Aparecida realiza dinâmicas de grupo e atividades em equipe e aposta em um processo avaliativo sensível ao objetivo de garantir a integralidade da escolarização de um aluno que tem dificuldade de frequentar a escola cotidianamente.

Sua formação em serviço na EJA, o exemplo de sua mãe e elementos de sua própria trajetória de formação são dimensôes centrais para entender o movimento que ela realiza em defesa de conteúdos rígidos a serem cumpridos para a tentativa de produzir relaçóes dialógicas que valorem no plano do currículo os interesses dos educandos, abrindo, por conseguinte, espaço para temas como drogas, gravidez na adolescência, alimentação, machismo. A prática curricular de Aparecida na EJA, portanto, transforma-se ao longo do tempo e é impactada pela possibilidade de atuar há bastante tempo na mesma escola, pelas vivências formativas que experimenta e pelas oportunidades pouco usuais do trabalho integrado com outra docente. Sua visão sobre as juventudes é a de um momento de grandes conflitos e de grande aprendizado. Ela reconhece como, a princípio, as relações interpessoais são interditadas por esses conflitos e que com o tempo aprende-se a lidar e a reconhecer a história de vida de cada um e enfatiza que ser professora da EJA a ensinou a ser mais flexível e mais humana.

Em síntese, a aparente contradição que reconhecemos na prática curricular de Cida testemunha que ainda que o aluno esteja autorizado a participar do processo de seleção curricular, sua atuação se dá em determinadas margens definidas pela afinidade que a docente apresenta por temas em saúde e meio ambiente, pelas sugestôes de conteúdos que os livros didáticos promovem, pelos contornos mais estáveis que a disciplina escolar impóe na definição do elenco de conteúdos que será tratado na escola e pela dificuldade de trabalhar em parceria com professores de outras áreas disciplinares e pelos próprios limites materiais da realidade da escola.

O movimento que se realiza no processo de definição curricular é complexo e pendula tanto na direção contrária de quem é o jovem da EJA, quanto na intenção de ir ao seu encontro. Isso se dá porque a necessidade de atender os educandos e lidar com acontecimentos transcorridos em aula estão sempre presentes, a tensionar as escolhas que a professora faz. Em uma ocasião observada em sala de aula, por exemplo, um aluno mostrou-se agressivo com a professora, sendo desrespeitoso ao se referir a atributos físicos do corpo feminino. Ao invés de 
confrontá-lo diretamente, na aula seguinte Cida abordou a questão da violência contra a mulher, escapando completamente das arquiteturas curriculares mais correntes que a disciplina Ciências assume na escola.

A professora reage às situações, mas é incapaz de escapar totalmente à estrutura. A dialética do currículo que a professora pratica é o testemunho do exercício de sua autonomia situada, isto é, dos esquemas possíveis de decisóes tomadas pela professora diante da realidade concreta. Há autonomia, mas há margens. Conforme assinala Sacristán (2000), cada professora ou professor, situado em sua experiência concreta, realiza e reage a essas dimensóes do trabalho curricular de forma diversa ao longo de sua vida profissional. A professora afeta o currículo e é afetada por ele. Nesse movimento, disputa pela presença do jovem no território do currículo. Nos limites da sociedade capitalista, ganha e perde. Cada vez mais precisamos nos questionar o quanto perde e o preço que as juventudes pagam por isso.

\section{AGRADECIMENTOS}

À professora Maria Aparecida e sua escola pela parceria que tornou essa pesquisa possível. Ao coletivo GRUPPEEJA. À FAPEMIG.

\section{REFERÊNCIAS}

ANDRÉ, M. E. D. A. Etnografia da prática escolar. Campinas: Papirus, 1995.

ARROYO, M. G. Balanço da EJA: o que mudou nos modos de vida dos jovens - adultos populares? Revista de Educação de Jovens e Adultos, V. I; 2007.

ARROYO, M. G. Currículo, território em disputa. 5a ed. Petrópolis: Vozes, 2013.

ARROYO, M. G. Passageiros da Noite do trabalho para a EJA - Itinerários pelo direito a uma vida justa. Petrópolis: Vozes, 2017.

BRASIL. Diretrizes Curriculares Nacionais para a Educação de Jovens e Adultos. Resolução CNE/CEB № 1, de 5 de Julho de 2000. Disponível em:http://portal.mec.gov.br/cne/arquivos/pdf/CEB012000.pdf. Acesso em: 12 Jul. 2020.

BRASIL. Proposta Curricular para a Educação de Jovens e Adultos: Segundo segmento do ensino fundamental: introduçãao. Ministério da Educação. Secretaria de Educação Fundamental, 148 p, i v. 1, 2002. Disponível em:http:// portal.mec.gov.br/secad/arquivos/pdf/eja_livro_01.pdf. Acesso em: 25 Jun. 2020.

CARRANO, P. C. R. Juventudes: as identidades são múltiplas. Movimento: Revista da Faculdade de Educação da Universidade Federal Fluminense, Niterói-RJ, n. 01, 2000.

CARRANO, P. Educação de Jovens e Adultos e juventude: O desafio de compreender os sentidos da presença dos jovens na escola da "segunda chance”. REVEJ@- Revista de Educação de Jovens e Adultos [revista eletrônica], v.1, p.55-67, 2007.

CASSAB, C. Contribuição à construção das categorias jovem e juventude: uma introdução. Locus: revista de história, Juiz de Fora, v. 17, n. 02, p. 145-159, 2011.

CASSAB, M. Educação de Jovens e Adultos, Educação em Ciências e Currículo: diálogos potentes. Educação em Foco, Juiz de Fora, v. 21, p. 13-38, 2016.

DAYRELL, J. A escola "faz" as juventudes? Reflexóes em torno da socialização juvenil. Educ. Soc., Campinas, v. 28, n. 100-Especial, p. 1105-1128, 2007.

FREIRE, P. Pedagogia do Oprimido. Rio de Janeiro: Ediçóes Paz e Terra, 1987.

FREIRE, P. Pedagogia da Autonomia: Saberes Necessários à Prática Educativa. 36 ed. São Paulo: Paz e Terra. Coleção Saberes. 1996.

GOODSON, I. A construção social do currículo. Lisboa: Educa, 1997. 
GOODSON, I. Currículo: teoria e história. Petrópolis: vozes, 2008.

GOODSON, I. Narrativas em Educação: a Vida e a Voz dos Professores. Porto: Ed. Porto, 2015.

JUIZ DE FORA. Resolução $N^{\circ} 25$ de 26/11/2008. Estabelece normas para organização e funcionamento das escolas municipais e dá outras providências. Disponível em: https://jflegis.pjf.mg.gov.br/c_norma.php? chave=0000030703. Acesso em: 18 Jun. 2020.

JUIZ DE FORA. Proposta Curricular: Educação de Jovens e Adultos. Juiz de Fora: Secretaria de Educação, 2012. Disponível em: https://www.pjf.mg.gov.br/secretarias/se/escolas_municipais/curriculos/arquivos/miolo_eja.pdf. Acesso em: 18 Jun. 2020.

KUTTER, A. P. Z. A Educação em Ciências Biológicas na Educação de Jovens e Adultos (EJA): Uma experiência etnográfica na escola. Dissertação (mestrado em Educação em Ciências) - Programa de pós-graduação Educação em ciências - química da vida e saúde. Universidade Federal do Rio Grande do Sul, Porto alegre, 2010.

MATTOS, C. L. G. e CASTRO, P. A. Etnografia e educação: conceitos e usos. Campina Grande: EDUEPB, 2011.

MEDEIROS, T. C. F. Experiências e expectativas de jovens estudantes: Uma abordagem do processo de juvenilização na EJA. 2018. 46f. Monografia de conclusão de curso. Universidade Federal da Paraíba, Centro de Ciências Agrárias, 2018.

MEIHY, J. C. S. B; HOLANDA, F. História Oral. Como fazer, como pensar. São Paulo: Contexto, 2007.

NASCIMENTO, A. S. O que dizem os educandos da EJA sobre a escola e o currículo de biologia. 2018. 149f. Dissertação (Mestrado em Educação) - Universidade Federal de Juiz de Fora, Juiz de Fora, 2018.

NÓvOA, A. Vidas de Professores. Porto: Editora Porto, 1995.

SACRISTÁN, J. G. O currículo: Uma reflexão sobre a prática. Porto Alegre: ArtMed, 2000.

SILVA, F. e MAIA, S. F. Narrativas autobiográficas: interfaces com a pesquisa sobre formação de professores. Anais do VI Encontro do Programa de Pós-Graduação da UFPi, Teresina, 2010. Disponível em:http://www.leg.ufpi.br/ subsiteFiles/ppged/arquivos/files/VI.encontro.2010/GT.1/GT_01_22.p

SOUSA, M. G. S.; CABRAL, C. A narrativa como opção metodológica de pesquisa e formação de professores. Horizontes, São Paulo, v. 33, n. 2, p. 149-158, 2015.

SPOSITO, M. P. Os jovens no Brasil: desigualdades multiplicadas e novas demandas públicas. São Paulo: Ação Educativa, 2003.

TARDIF, M. O trabalho docente: elementos para uma teoria da docência como profissão de interaçóes humanas. Petrópolis: Vozes, 2009.

\section{NOTAS}

1 Esse texto socializa parte da pesquisa de mestrado "A complexidade curricular no fazer de uma educadora de ciências em uma EJA cada vez mais jovem", disponível em: https://repositorio.ufff.br/jspui/bitstream/ufff/11339/1/ anacarolinacostaresende.pdf. Acesso em: 17 fev. 2021. A referida pesquisa também integra o estudo "O ensino de Ciências e Biologia na EJA: leituras curriculares", financiado pela FAPEMIG.

2 A EJA no município de Juiz de Fora está organizada em fases (I a VIII). Cada fase ocupa um semestre letivo. Administrativamente é previsto um número mínimo e máximo de alunos por turma em cada fase, a saber: nas fases de I a IV, 25 e 30 alunos, respectivamente; nas fases V e VI, 30 e 35, e nas fases VII e VIII, 35 e 40 . É previsto que, na impossibilidade da manutenção de turmas seriadas, novos critérios sejam adotados. Turmas multisseriadas (4 fases de 15 a 17 alunos; turmas trisseriadas de 18 a 20 alunos e turmas bisseriadas de 20 a 25 alunos) (Juiz de Fora, 2008).

3 Coleção EJA Moderna. Editora moderna, 2014. 


\section{Ana Carolina Costa Resende}

Doutoranda em Educação. Professora da Educação Básica na SEEMG em Juiz de Fora, Minas Gerais, Brasil. Integrante do GRUPPEEJA.

E-mail: acarolina.rcosta@gmail.com

\section{Mariana Cassab}

Doutora em Educação. Professora Associada da Universidade Federal de Juiz de Fora, Minas Gerais, Brasil. Coordenadora do GRUPPEEJA.

E-mail: mariacassab@yahoo.com.br

Contato:

Mariana Cassab

Faculdade de Educação e Pedagogia | UFJF

Rua José Lourenço Kelmer - São Pedro Juiz de Fora, MG | Brasil

CEP 36.036-900

Editor responsável:

Fábio Augusto Rodrigues Silva 